\title{
Multicentric tracheobronchial and oesophageal granular cell myoblastoma
}

\author{
DENIS J O'CONNELL, ${ }^{1}$ HEBER MaCMAHON, ${ }^{1}$ AND THOMAS R DE MEESTER ${ }^{2}$ \\ From the Departments of Radiology ${ }^{1}$ and Surgery, ${ }^{2}$ The University of Chicago, Chicago, \\ Illinois 60637, USA
}

\begin{abstract}
O'Connell, D J, MacMahon, H, and De Meester, T R (1978). Thorax, 33, 596-602. Multicentric tracheobronchial and oesophageal granular cell myoblastoma. Two patients with multiple intrathoracic granular cell myoblastomas are described. In one case multiple tumours were present in the major airways and oesophagus. The patient presented with recurrent pulmonary infections and stridor due to airway obstruction. In the other case dysphagia caused by multiple oesophageal granular cell myoblastomas was the major symptom. Granular cell myoblastoma is a rare tumour of neurogenic origin with a characteristic histological appearance. The pattern of multiple tracheobronchial and oesophageal tumours is uncommon and forms the basis of this report.
\end{abstract}

Granular cell myoblastoma (GCM) is a rare tumour of neurogenic origin, most often found in the skin, tongue, or larynx (Vance and Hudson, 1969; Oparah and Subramanian, 1976). Other less common locations include the bile ducts, breast, thyroid, and vagina (Serpe et al, 1960; Umansky and Bullock, 1968; Ostermiller et al, 1970). Multiple tumours are reported to occur in $7 \%$ of these cases (Moscovic and Azar, 1967). There have been few reports of tracheobronchial or oesophageal locations for these tumours, and multiple intrathoracic lesions are exceptionally uncommon. We have recently encountered two patients who presented with symptoms referable to multiple granular cell myoblastomas in the larynx, trachea, bronchus, and oesophagus.

\section{Case reports}

CASE 1

A 36-year-old black woman presented in 1971 with a productive cough of three months' duration. A chest radiograph showed patchy consolidation in the left upper lobe, which cleared after a ten-day course of penicillin. Two subsequent left upper lobe infections led to a bronchogram, which showed a smooth, $2 \mathrm{~cm}$ submucosal mass at the junction of the left main and lower lobe bronchi (fig 1). Lingular bronchiectasis was also shown. Bronchoscopy confirmed these find- $\stackrel{\mathscr{Q}}{\mathscr{Q}}$ ings, and biopsy of the endobronchial mass showed $\overrightarrow{\vec{\theta}}$ histological features characteristic of GCM. The $\frac{3}{3}$ tumour was curetted through the bronchoscope.

The patient was seen again in 1974 after a haematemesis. This was considered to be due to alcoholic gastritis. Results of a barium examination of the oesophagus and stomach, performed $\underset{x}{\stackrel{0}{\nu}}$ at that time, were normal.

In May 1977 she complained of mild dyspnoea, and a chest radiograph showed consolidation in $\delta$ the lingula, which cleared after antibiotic treat- $₹$ ment. Two months later, however, she presented 윽 again with severe stridor, dyspnoea, and dysphagia. The chest radiograph was normal, but tomograms of the trachea and major airways showed a large, $\mathrm{N}$ lobulated mass in the upper trachea, narrowing the or lumen considerably (fig 2). Bronchoscopy con- N firmed the tomographic findings, and an additional N tumour mass was seen in the larynx. Biopsy of the 0 tracheal mass showed granular cell myoblastoma. An upper gastrointestinal examination showed $\stackrel{\odot}{\odot}$ three separate submucosal masses in the mid and $\stackrel{\oplus}{\rightarrow}$ lower oesophagus (figs 3(a) and (b)). At thoracotomy 0 the affected segment of trachea and the solitary $\vec{D}$ laryngeal tumour were resected. Later, the patient $\Phi$ developed severe tracheal stenosis at the operation $\mathbb{\mathbb { D }}$ site, but further treatment was refused. She died $\frac{2}{\sigma}$ after a massive aspiration of stomach contents. At 


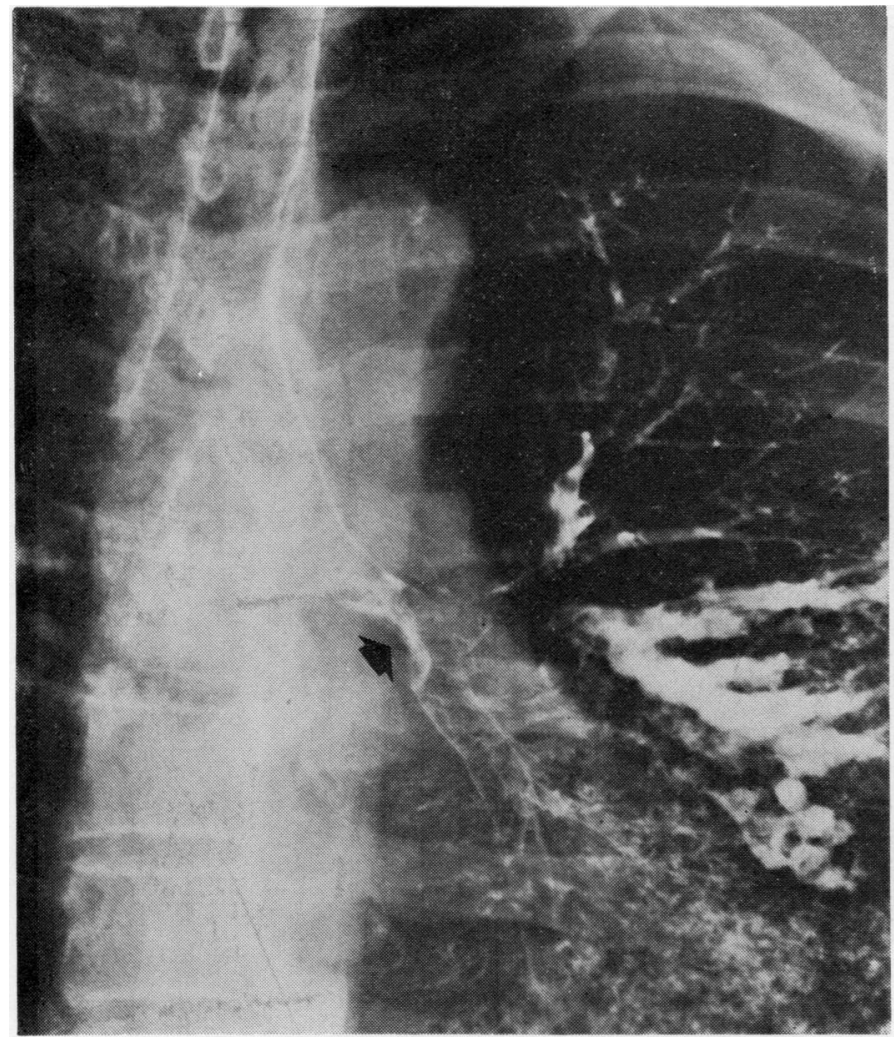

Fig 1 Case 1. Bronchogram shows submucosal mass (arrow) and lingular bronchiectasis. 


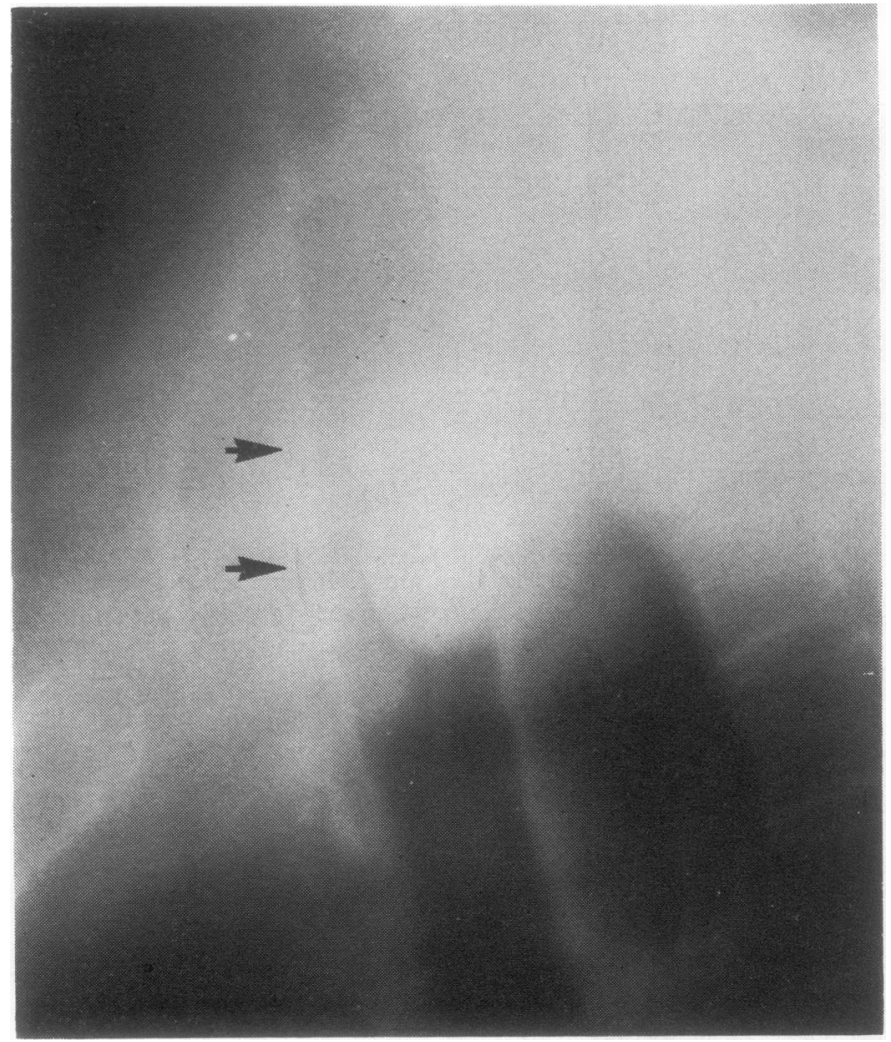

Fig 2 Case 1. Lateral tomogram shows a lobulated mass attached to posterior wall of trachea (arrows). 


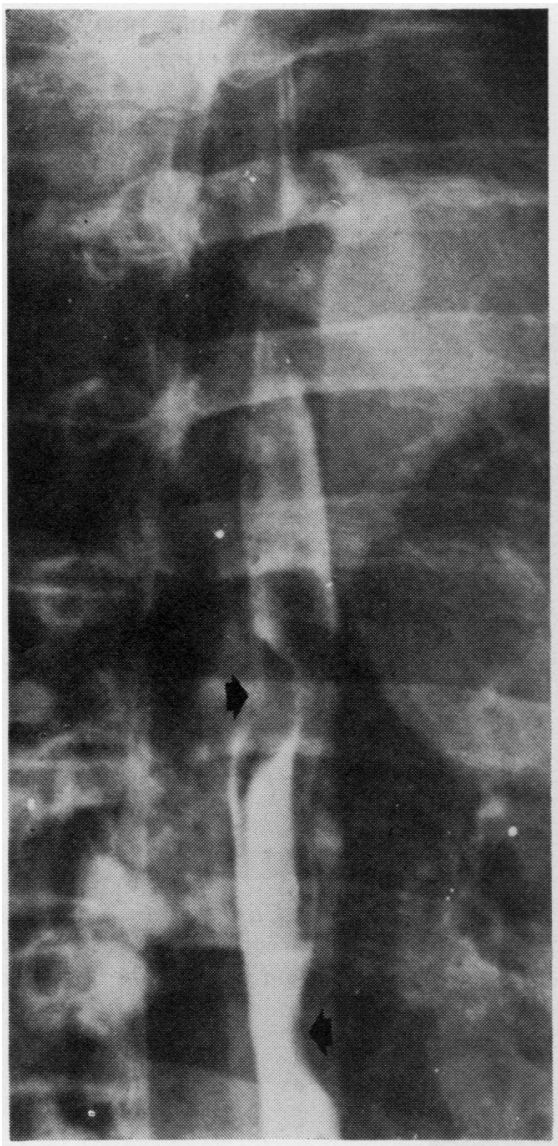

(a)

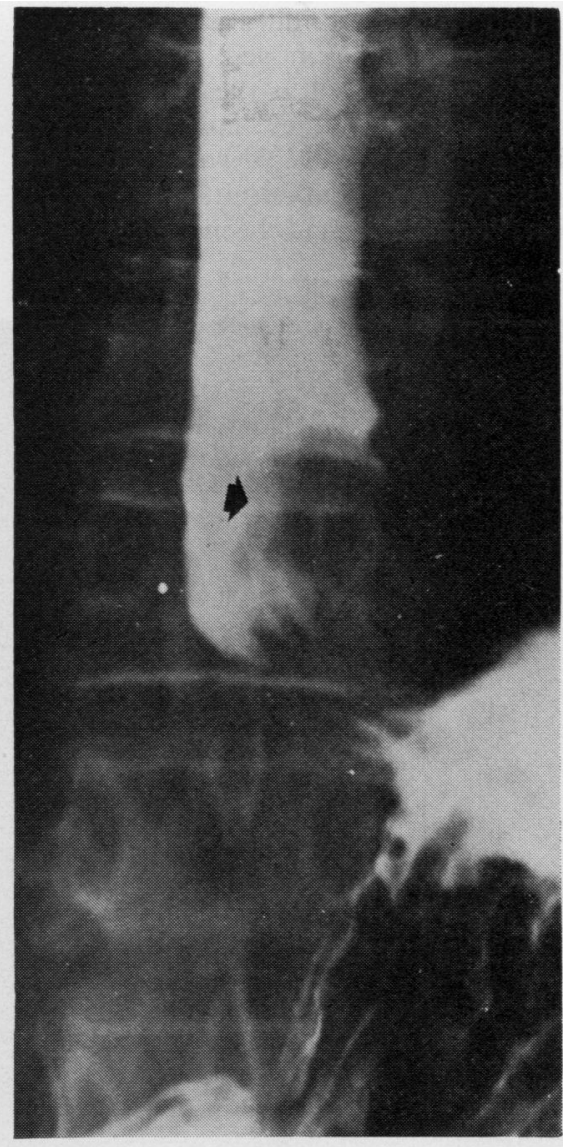

(b)

Fig 3(a) and (b) Case 1. Barium examination shows two submucosal masses (arrows) in mid-oesophagus and another mass distally. 
necropsy, in addition to the tumours found in vivo, there were three small tumours in the stomach and another in the pericardium.

\section{CASE 2}

This 56-year-old white woman presented with a two-year history of worsening dysphagia and intermittent substernal chest pain. Investigation at another institution in January 1976 showed a submucosal mid-oesophageal mass. Oesophageal manometry had indicated diffuse oesophageal spasm. The mass was not removed.

In July 1976 she presented at the University of Chicago hospitals and clinics complaining of severe dysphagia and considerable weight loss. On direct questioning, the patient admitted that about 20 small skin "tumours" had been removed 10 years previously. These tumours had been calledo "myoblastomas." Physical examination was un-으 remarkable apart from obvious recent weight loss. $\frac{\bar{s}}{\sigma}$ The chest radiograph was normal. Barium ex- $\mathbb{\AA}$ amination showed a large, smooth submucosalo mass in the mid-oesophagus and another small submucosal mass just above the gastro-oesophageal. junction (fig 4). Oesophageal manometry showed $\overrightarrow{\vec{\omega}}$ a high-pressure zone in the lower oesophagus, $\omega_{\infty}$ which failed to relax during swallowing. There was no effective primary peristaltic wave, and $\mathrm{w}_{\omega}^{\times}$ multiple tertiary contractions were noted. This was considered to be diagnostic of achalasia. A Heller's $r$ myotomy was performed, and the two submucosal\& tumours were removed. Histological examinationo showed granular cell myoblastoma. The tumours $\rightarrow$ were very cellular with pleomorphic, ando

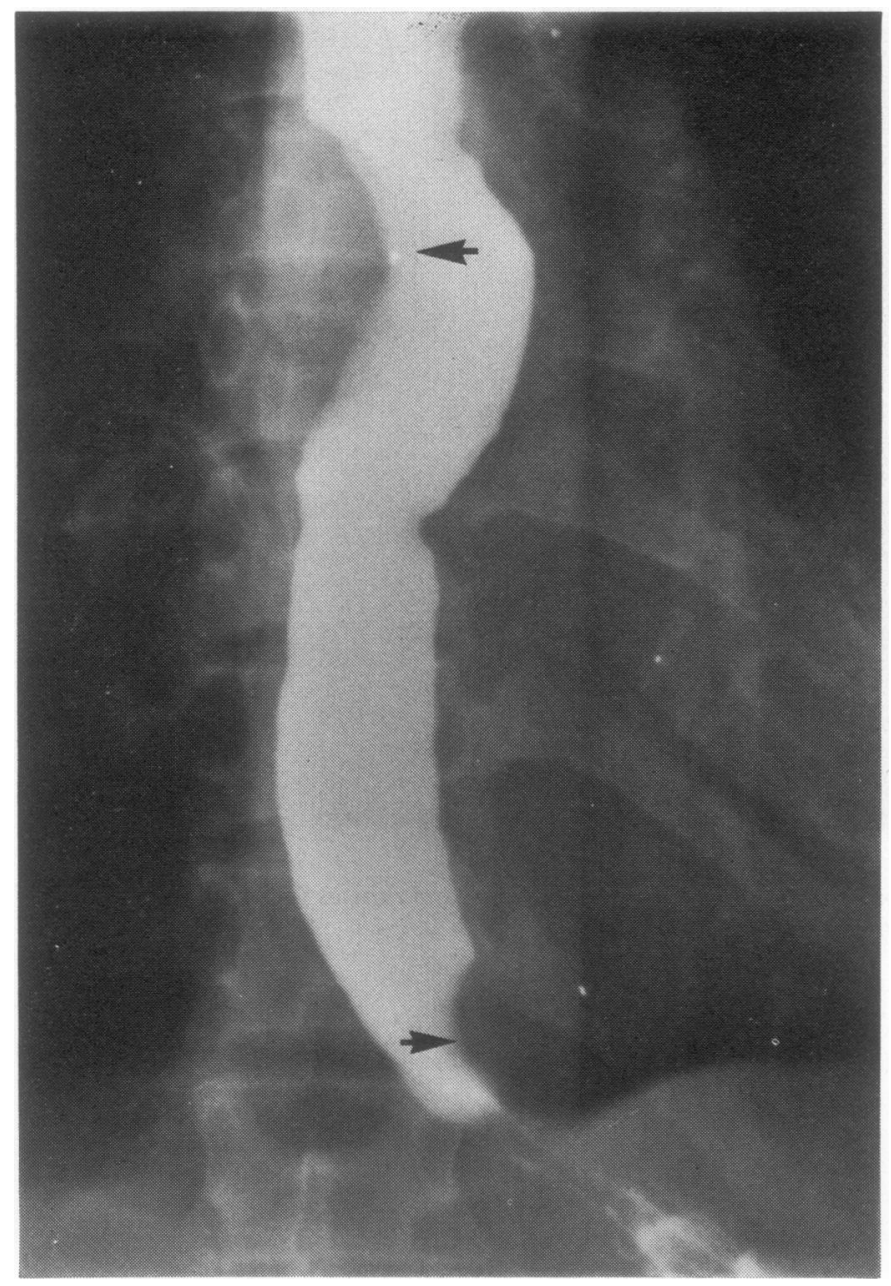

Fig 4 Case 2. Barium examination shows a large mid-oesophageal submucosalô mass and another mass just above gastro-oesophageal junction (arrows). 
occasionally bizarre, vesicular nuclei with prominent nucleoli. These histological features are associated with aggressive tumours and were thought to indicate malignant potential. Six months after operation the patient remains well and has no symptoms.

\section{Discussion}

Granular cell myoblastoma of the tracheobronchial tree is rare, representing less than $2 \%$ of all myoblastomas (Murphy et al, 1949; Umansky and Bullock, 1968; Oparah and Subramanian, 1976). Multiple lesions in the major airways are uncommon. Although lesions from the tongue to the rectum have been described, only 13 cases of GCM located in the oesophagus have been reported (Mansour et al, 1977). Multiple oesophageal tumours have not been previously recorded.

Original reports suggested that these tumours arose from embryonic muscle cells (Abrikossoff, 1926), and for many years a myogenic derivation was accepted. At present, however, it is generally accepted that granular cell myoblastoma originates from Schwann cells (Fisher and Wechsler, 1962; Moscovic and Azar, 1967; Mansour et al, 1977).

The histological appearance is characteristic. The lesions are very cellular, with sheets or clumps of large polyhedral cells containing abundant granular eosinophilic cytoplasm and small dark vesicular nuclei. The cells tend to be closely packed, have varying shapes, and are arranged in a syncytial fashion (fig 5) (Sobel and Churg, 1964). A characteristic pseudo-epitheliomatous hyperplasia of overlying epithelium is seen in a high proportion of cases and may lead to an erroneous diagnosis of squamous cell carcinoma (Moscovic and Azar, 1967; Booth and Osborn, 1970).

The gross appearance of endobronchial GCM ranges from a plaque-like thickening of the mucosa to a polypoid mass. The lesions range in size from $3 \mathrm{~mm}$ to $6.5 \mathrm{~cm}$ (Oparah and Subramanian, 1976). Endobronchial GCM is considered a benign tumour, and no case of distant metastasis has been reported. Extrathoracic tumours, however, may occasionally metastasise (Moscovic and Azar, 1967).

Clinically, tracheal and endobronchial GCM presents in a non-specific fashion with dyspnoea, wheeze, and episodes of infection. The chest radiograph may show lobar or segmental atelectasis or consolidation distal to the obstructing lesion. Recurrent infection may cause bronchiectasis as seen in case 1 . Bronchotomography may show the endotracheal or endobronchial extension of the mass, although occasionally the submucosal mass will be plaque-like and escape detection on tomography. Bronchoscopy or bronchography will

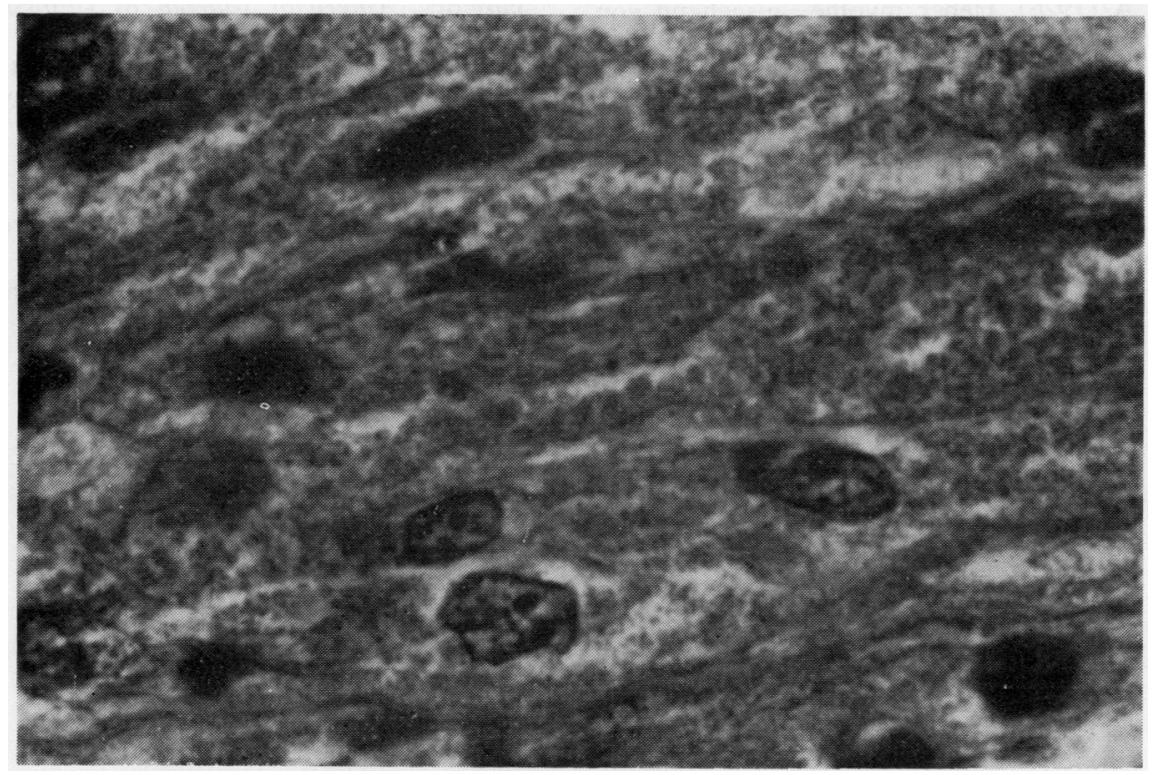

Fig 5 Case 1. Histological section of lower oesophageal lesion shows characteristic findings of closely packed polyhedral cells containing many eosinophilic granules in cytoplasm and small darkly staining nuclei $(H$ and $E \times 415)$. 
usually show the endobronchial extent of the tumour mass, which may be mistaken for a bronchial adenoma. Occasionally the tumour may grow along the bronchial tree to present as a non-specific parenchymal mass lesion (Teplick et al, 1975).

Oesophageal granular cell myoblastoma may be asymptomatic or the patient may complain of dysphagia with substernal discomfort. As in case 2, the history of dysphagia may extend over a prolonged period (Crawford and De Bakey, 1953).

The treatment of choice for tracheobronchial or oesophageal GCM is surgical excision. Endoscopic removal of the tumour is not advised as recurrence is likely (Peterson et al, 1957). This is because most of the tumour mass is submucosal so that total removal via the bronchoscope or oesophagoscope is difficult. Furthermore, endoscopic biopsy of the submucosal oesophageal mass may be complicated by perforation, infection, and mediastinitis.

The differential diagnosis of multiple tracheobronchial and oesophageal masses includes leiomyomatosis, metastases, amyloidosis, and neurofibromatosis. Despite its rarity, granular cell myoblastoma should also be considered, especially in a patient with an associated skin or tongue mass.

\section{References}

Abrikossoff, A (1926). Ueber myome, ausgehend von der quergestrieften willkürlichen muskulatur. Virchows Archiv für Pathologische Anatomie und Physiologie, 260, 215-233.

Booth, J B, and Osborn, D A (1970). Granular cell myoblastoma of the larynx. Acta Oto-Laryngologica, 70, 279-293.

Crawford, E S, and De Bakey, M E (1953). Granular cell myoblastoma-two unusual cases. Cancer, 6, 786-789.
Fisher, E R, and Wechsler, H (1962). Granular ced myoblastoma-a misnomer. Cancer, 15, 936-954. 든

Mansour, K A, Hatcher, C R, and Haun, C L (1977 Benign tumors of the esophagus: experience with 20 cases. Southern Medical Journal, 70, 461-465.

Moscovic, E A, and Azar, H A (1967). Multip局 granular cell tumors ("myoblastomas"). Cancer 20, 2032-2046.

Murphy, G H, Dockerty, M S, and Broders, C (1949) Myoblastoma. American Journal of Pathology, 2 $1157-1182$.

Oparah, S S, and Subramanian, V A (1976). Granula cell myoblastoma of the bronchus: report of twe cases and review of the literature. Annals of Thoracic Surgery, 22, 199-202.

Ostermiller, W E, Comer, T P, and Barker, W P (1970). Endobronchial granular-cell myoblastoma Annals of Thoracic Surgery, 9, 143-148.

Peterson, P A, Soule, E H, and Bernatz, P E (1957ه Benign granular-cell myoblastoma of the bronchus report of two cases. Journal of Thoracic and Cardi vascular Surgery, 34, 95-99.

Serpe, S J, Todd, D, and Baruch, H (1960d0 Cholecystitis due to granular-cell myoblastoma of the cystic duct. American Journal of Digestive Diseases, 5, 824-826.

Sobel, H J, and Churg, J (1964). Granular cells an granular cell lesions. Archives of Pathology, $7 \frac{5}{6}$ 132-141.

Teplick, J G, Teplick, S K, and Haskin, M E (1975 Granular cell myoblastoma of the lung. Americam Journal of Roentgenology, 125, 890-894.

Vance, S F, and Hudson, R P, jun (1969). Granular cell myoblastoma: clinicopathological study of patients. American Journal of Clinical Patholog 52, 208-215.

Umansky, C, and Bullock, W K (1968). Granular ce myoblastoma of the breast. Annals of Surgery, 16\& 810-813.

Requests for reprints to: Dr Denis J O'Connell, De partment of Radiology, The University of Chicage 950 East 59th Street, Chicago, Illinois 60637. 